\title{
Pengaruh Pemberian Jus Tomat Terhadap Tekanan Darah Pada Remaja Putri \\ Lulu' Luthfiya $^{1}$, Kartika Pibriyanti ${ }^{1}$, Durrotun Nafisah ${ }^{1}$, Zid Amalia Khusniyati ${ }^{1}$, Sayidatu Ulinuha $^{1}$, Lola Zahro ${ }^{1}$, Laila Sari Mawadati ${ }^{1}$, Nuryuni Ekawidya Widodo ${ }^{1}$ \\ ${ }^{1}$ Program Studi Ilmu Gizi, Fakultas Ilmu Kesehatan, Universitas Darussalam Gontor, Sambireo, Mantingan, Ngawi, Jawa Timur, 63261 Email : lululuthfiya1801@gmail.com
}

Tanggal Submisi: 21 Maret 2020; Tanggal Penerimaan: 17 November 2021

\begin{abstract}
ABSTRAK
Latar Belakang : Hipotensi dan hipertensi merupakan dua permasalahan dengan prevalensi yang terus mengalami peningkatan pada usia remaja dan salah satu buah dengan kandungan likopen tinggi yang berpengaruh terhadap tekanan darah. Tujuan : mengetahui pengaruh pemberian jus tomat terhadap tekanan darah. Metode : Desain penelitian ini adalah quasy eksperimental dengan rancangan one group pre test post test. Sampel penelitian masing-masing sebanyak 22 responden yang diambil dengan cara purpossive sampling. Pemberian intervensi dilaksanakan selama 7 hari berturu turut. Aenalisis data yang menggunakan software program STATA 13.1 dengan menggunakan uji paired T-Test. Hasil : Setelah dilakukan intervensi terjadi perubahan signifikan $(\mathrm{P}<0,05)$ tekanan darah baik sistol dan diastol pada responden hipertensi dan hipotensi. Kesimpulan : Jus tomat berpengaruh terhadap tekanan darah.
\end{abstract}

Kata kunci : Hipertensi, Hipotensi, Jus Tomat, Remaja Putri

\begin{abstract}
Hypotension and hypertension are two problems with a prevalence increase in adolescence continually and one of fruits with high lycopen which affects blood pressure is tomato. Objective : Determining the effect of tomato juice on blood pressure. Methods: The design of this study was quasy-experimental with one group pre test post test design. The sample of research consisted of 22 respondents who collected by purposive sampling. The intervention was collected for 7 days. Data was analysed by STATA 13.1 software program using paired T-Test. Results: There was a diffeences significanly $(P<0.05)$ before and after intervention, both systolic and diastolic blood pressure in hypertensive and hypotensive respondents. Bottom Line: Tomato juice has an effect on blood pressure
\end{abstract}

Key word: Female teenager, Hypertension, Hypotension, Tomato juice

ISSN 1979-7621 (Print). ISSN 2620-7761 (Online)

DOI 10.23917/jk.v14i2.14787 


\section{Pendahuluan}

Hipotensi dan hipertensi merupakan dua permasalahan dengan prevalensi yang terus mengalami peningkatan pada usia remaja. Menurut Anyaegbu, prevalensi hipertensi pada anak anak dan remaja diperkirakan mengalami peningkatan sekitar $1-5 \%$ dimana kejadian hipertensi yang dianggap sebagai penyakit dewasa kini telah menjadi semakin umum pada populasi anak dan remaja (Anyaegbu \& Dharnidharka, 2015). Di Indonesia, diketahui bahwa sebanyak $8,7 \%$ remaja mengalami hipertensi (Badan penelitian dan pengembangan, 2013). Sedangkan, remaja putri juga diketahui sangat beresiko mengalami tekanan darah rendah. Hipotensi dan hipertensi yang terjadi pada usia remaja sering tidak disadari dan akan berdampak terhadap kesehatan di usia dewasa. Usia remaja rentan mengalami kejadian hipertensi dan hipotensi disebabkan perubahan gaya hidup dan status gizi (Merdianti, Hidayati, Asmoro, \& Kunci, 2019), selain itu kualitas tidur yang buruk pada remaja juga berpengaruh terhadap tekanan darah (Lumantow, Rompas, \& Onibala, 2016). Berdasarkan penelitian yang dilakukan oleh Rahmadini di Pondok Pesantren Putri diketahui bahwa sebanyak $71,1 \%$ remaja putri memiliki kualitas tidur yang tidak baik (Rahmadini, 2017).

Tomat merpakan buah dengan kandungan tinggi likopen yang berpengaruh terhadap tekanan darah. Kandungan likopen dan kalium pada tomat dapat menurunkan tekanan darah dan bekerja dalam mempengaruhi sistem renin angiotensin (Ismalia \& Zuraida, 2016). Penelitian yang dilakukan oleh Anita dan Ramdani menunjukkan bahwa mengonsumsi jus tomat dapat menurunkan tekanan darah tinggi (Anita, Suwandono, Ariyanti, Pramono, \& Kumorowulan, 2017) (Muhamad, Hidayat, \& Alfikrie, 2020). Di satu sisi, tomat mengandung sodium tinggi yang dapat meningkatkan tekanan darah. Berdasarkan penelitian yang dilakukan oleh Sriminanda, pemberian jus tomat yang dilakukan selama 7 hari menunjukkan bahwa terjadi peningkatan tekanan darah yang signifikan pada penderita hipotensi (Sriminanda et al., 2014). Nasution dalam penelitiannya juga mengatakan bahwa jus tomat yang mengndung likopen, biovlafonoid dan kadar garam tinggi dapat meningkatkan tekanan darah sistolik pada pasien hipotensi (Nasution \& Moona, 2018).

Berdasar penelitian-penelitian terdahulu dapat diketahui bahwa jus tomat memiliki manfaat dalam menormalkan tekanan darah, baik itu pada penderita hipertensi dan juga pada penderita hipotensi. Belum banyak penelitian dengan menggunakan jus tomat sebagai solusi untuk meningkatkan tekanan darah rendah. Sehingga pada penelitian kali ini bertujuan untuk mengetahui pengaruh pemberian jus tomat terhadap tekanan darah, baik pada remaja putri dengan tekanan darah tinggi ataupun dengan tekanan darah rendah.

\section{Metode Penelitian}

Desain penelitian ini adalah quasy eksperimental dengan rancangan one group pre test post test. Penelitian dilaksanakan pada bulan Agustus 2020 di Pondok Pesantren Putri dengan populasi seluruh santri putri yang berusia 11-14 tahun. Sampel penelitian masingmasing sebanyak 23 responden baik pada kelompok hipertensi dan kelompok hipotensi yang dihitung dengan menggunakan rumus pengukuran sampel hypotesis testing for a population mean.

Responden diambil dengan cara purpossive sampling, yaitu responden remaja putri di ukur tekanan darah dengan menggunakan sphygmanomneter dan tinggi badan dengan menggunakan microtoice. Hasil pengukuran kemudian dihitung dengan menggunakan pediatric blood pressure calculator. Responden yang memiliki tekanan darah sistol atau diastol tinggi dan tekanan darah sistol atau diastol rendah dijadikan sebagai sampel penelitian. Tahapan penelitian dimulai dengan pengukuran tekanan darah kemudian responden diberikan jus tomat sebanyak 150 gram dalam sehari dimana jus tomat diberikan selama 7 hari berturut turut, setelah itu tekanan darah responden di ukur kembali.

Analisis data yang menggunakan software program STATA 13.1. Analisis univariat digunakan untuk mendeskripsikan varabel penelitian sebelum dilakukan analisis bivariat. 
Untuk mengetahui pengaruh pemberian jus tomat terhadap tekanan darah tinggi dan tekanan darah rendah menggunakan uji paired T-Test dengan melalui tahap uji normalitas menggunakan spahiro wilk.

\section{Hasil dan Pembahasan Karakteristik Responden}

Tabel 1. Umur Responden

\begin{tabular}{ccccc}
\hline & \multicolumn{2}{c}{$\begin{array}{c}\text { Responden } \\
\text { hipertensi }\end{array}$} & \multicolumn{2}{c}{$\begin{array}{c}\text { Responden } \\
\text { Hipotensi }\end{array}$} \\
\hline Umur & $\mathrm{n}$ & $\%$ & $\mathrm{n}$ & $\%$ \\
\hline 12 & 15 & 68.2 & 9 & 40.91 \\
13 & 5 & 22.7 & 12 & 54.55 \\
14 & 2 & 9.1 & 1 & 4.55 \\
Jumlah & 22 & 100 & 22 & 100 \\
\hline
\end{tabular}

Sumber : Data primer

Secara umum distribusi responden lebih banyak berusia 12-13 tahun. Usia 12-13 tahun merupakan usia yang dikategorikan dalam remaja awal. Masa remaja terbagi menjadi 3 tahap yaitu remaja awal (12-15 tahun), remaja madya (15-18 tahun) dan remaja akhir (18-21 tahun) Permasalahan tekanan darah pada remaja terutama hipertensi merupakan salah satu faktor risiko penyakit kardiovaskular dan hipertensi pada usia dewasa (Varda, 2016). Perubahan pola makan, gaya hidup dan aktivitas fisik cenderung terjadi pada usia remaja awal, dimana terjadi peralihan dari masa anak-anak menjadi masa remaja. Hal tersebut memicu terjadi perubahan tekanan darah baik penurunan atau peningkatan (Merdianti et al., 2019).

Tabel 2. Tekanan darah sebelum dan setelah pemberian jus tomat pada responden hipertensi

\begin{tabular}{llll}
\hline & Mean \pm SD & Min - Max & P-value \\
\hline $\begin{array}{l}\text { Tekanan darah } \\
\text { sistol }\end{array}$ & & & \\
Sebelum (mmHg) & $121.3 \pm 4.17$ & $119.4-123.1$ & 0,0000 \\
Setelah (mmHg) & $105.6 \pm 8.51$ & $101.9-109.4$ & \\
\hline Tekanan darah & & & \\
diastol & & & \\
Sebelum (mmHg) & $76.04 \pm 7.47$ & $72.73-79.36$ & 0,0000 \\
Setelah (mmHg) & $68.18 \quad \pm$ & $10.14-63.69$ & \\
& 10.14 & & \\
\hline
\end{tabular}

\section{Sumber : Data primer}

Pemberian jus tomat berpengaruh terhadap tekanan sistol dan diastol pada responden dengan tekanan darah tinggi. Setelah dilakukan intervensi jus tomat selama 7 hari berturut turut terjadi penurunan tekanan darah. Penyebab utama terjadi hipertensi dikarenakan penyempitan arteri. Tomat merupakan makanan yang dapat dicari dengan mudah biaya rendah dan mengandung berbagai macam senyawa yang berpengaruh terhadap tekanan darah, sehingga dapat diimplementasikan dalam makanan sehari hari.

Kandungan buah tomat yang paling utama untuk menurunkan tekanan darah tinggi adalah kalium dan likopen (Rahayu, 2017). Selain itu, tomat juga mengandung asam butirat gammaamino tinggi (GABA) yang merupakan senyawa untuk menurunkan tekanan darah (Bhowmik \& Paswan, 2012).

Likopen (Lycopersicon esculemtum) yaitu merupakan karoteoid yang memberikan warna merah pada tomat dengan struktur kimia terdiri dari sebelas ikatan rangkap terkonjugasi sehingga yang bermanfaat untuk pelebaran artei, sebagai antioksidan dan menangkal radikal bebas (Raygoza, Moreno, \& Gomez, 2020). Kandungan likopen pada tomat selain sebagai antioksidan juga sebagai penyeimbang tekanan darah serta melenturkan sel saraf jantung yang kaku karena sumbatan kolesterol dan gula darah. Likopen dapat menurunkan tekanan darah dengan cara menghambat penyerapan oksigen reaktif terhadap endotel yang mengganggu dilatasi pembuluh darah (Ismalia \& Zuraida, 2016).

Likopen dalam tomat akan lebih dapat diserap oleh tubuh bila bila dalam bentuk olahan jus dibandingkan dengan buah segar. Penyerapan likopen dalam buah segar $4 \mathrm{x}$ lebih rendah dibandingkan dengan jus tomat (Bhowmik \& Paswan, 2012). Kandungan kalium yang tinggi pada tomat dapat menurunkan tekanan darah. Kalium berpengaruh terhadap sistem renin angiotensindiaman akan menghambat perubahan angotensinogen menjadi angiotensinogen I yang menyebabkan vasodilatasi pembuluh darah dan mengakibatkan tekanan darah menurun, selan itu, kalium menyebabkan relaksasi dinding pembuluh darah (Septimar, Rustami, \& Wibisono, 2020). 
Tabel 3. Tekanan darah sebelum dan setelah pemberian jus tomat pada responden hipotensi

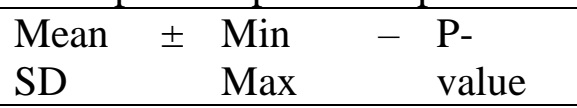

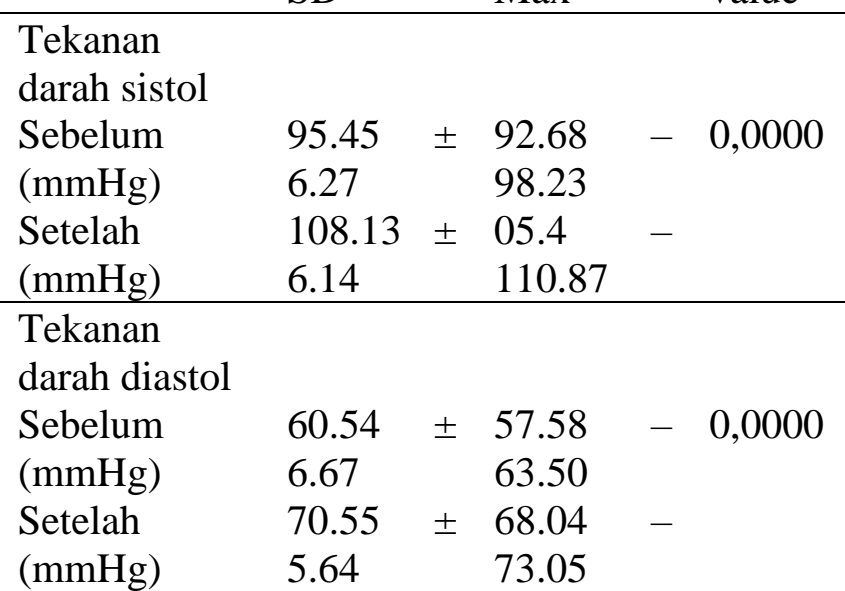

Sumber : Data primer

Pemberian jus tomat berpengaruh terhadap tekanan sistol dan diastol pada responden dengan tekanan darah rendah, yaitu setelah dilakukan intervensi selama 7 hari berturut turut dengan memberikan jus tomat menyebabkan erjadinya peningkatan tekanan darah. Nasution dalam penelitiannya juga menunjukkan bahwa pemberian jus tomat dapat meningkatkan tekanan darah baik sistol sebesar 3,148 kali, sementara pada tekanan diastol mengalami kenaikkan sebesar 2,121 kali. Jus tomat memiliki kandungan likopen, bioflavanoid dan kadar garam tinggi sehingga dapat meningkatkan tekanan darah (Nasution \& Moona, 2018).

\section{Kesimpulan}

Intervensi pemberian jus tomat selama 7 hari berpengaruh terhadap tekanan darah yaitu jus tomat dapat menormalkan tekanan darah. Pada responden dengan hipertensi pemberian jus tomat dapat menurunkan tekanan darah dan pada responden dengan hipotensi dapat meningkatkan tekanan darah.

\section{Referensi}

Anita, T., Suwandono, A., Ariyanti, I., Pramono, N., \& Kumorowulan, S. (2017). Effect of Consuming Tomato (Lyoperisum Commune) Juice in Lowering Blood Pressure in Pregnant Mothers With Hypertension. Belitung Nursing Journl, 3(6), 707-711.

Anyaegbu, E., \& Dharnidharka, V. (2015). Hypertension in The Teenager. Pediatr Clin North Am, 61(1), 131-151. https://doi.org/10.1016/j.pcl.2013.09.011.HYPERTENSION

Badan penelitian dan pengembangan. (2013). Riset Kesehatan Dasar (RISKESDAS) 2013.

Bhowmik, D., \& Paswan, S. (2012). Tomato-A Natural Medicine and Its Health Benefits Introduction : Tomatoes are a member of Tomato-A Natural Medicine and Its Health Benefits. Phytojournal, 1(1).

Ismalia, N., \& Zuraida, R. (2016). Efek Tomat (Lycopersion esculentum Mill) dalam Menurunkan Tekanan Darah Tinggi Nada. MAJORITY, 5, 107-111.

Lumantow, I., Rompas, S., \& Onibala, F. (2016). Hubungan Kualitas Tidur dengan Tekanan Darah pada Remaja di Desa Tombasian Atas Kecamatan Kawangkoan Barat. E-Journal Keperawatan, 4(1).

Merdianti, R., Hidayati, L., Asmoro, C. P., \& Kunci, K. (2019). Hubungan Status Nutrisi dan Gaya Hidup terhadap Tekanan Darah pada Remaja di Kelurahan Lidah Kulon Kota Surabaya. Junal Ners Dan Kebidanan, 6, 218-226. https://doi.org/10.26699/jnk.v6i2.ART.p218 
Muhamad, R., Hidayat, U., \& Alfikrie, F. (2020). Efek Pemberian 150 Gram Tomat (Solanium Lycoperisum) Terhadap Tekanan Darah Penderita Hipertensi. Borneo Nursing Journal, 2(1), 55-60.

Nasution, A. S., \& Moona, N. N. (2018). Pemanfaatan Jus Alpukat dan Jus Tomat Sebagai Upaya Untuk Menaikkan Tekanan Darah Rendah. Jurnal Gizi KH, 1(1), 32-37.

Rahayu, R. M. (2017). Pengaruh Pemberian Jus Tomat Terhadap Tekanan Darah Pada Wanita Menopause dengan Hipertensi di Posyandu Kantil The Influence of Tomato Juice on Blood Pressure In Menopause Women With Hypertension in Posyandu Kantil. Journal of Health Science and Prevention, 1(1), 52-57.

Rahmadini, O. (2017). Hubungan Antara Pola Tidur Terhadap Tekanan Darah pada Remaja SMA di Pondok Pesantren Al-Munawwir Krapyak Yogyakarta.

Raygoza, N. P., Moreno, E. R., \& Gomez, S. R. (2020). Correlation between Lycopene Intake and Blood Pressure in Healthy Adults from Correlation between Lycopene Intake and Blood Pressure in Healthy Adults from Celaya, Mexico. Journal of Advances in Medicine and Medical Research, (July). https://doi.org/10.9734/jammr/2019/v30i530193

Septimar, Z. M., Rustami, M., \& Wibisono. (2020). Pengaruh Pemberian Jus Tomat Terhadap enurunan Tekanan Darah pada Penderita Hipertensi di Tangerang Tahun 2020: A Literature Review. Jurnal Menara Medika, 3(1), 66-73.

Sriminanda, L., Dewi, A. P., Indriati, G., Studi, P., Keperawatan, I., \& Riau, U. (2014). Efektivitas pemberian jus tomat terhadaptekanan darah pada penderita hipotensi. Jurnal Online Mahasiswa, 1(1), 1-8.

Varda, N. M. (2016). Hypertension in Adolescent. Scientific Research Publishing, (August), 10651074. 